Check for updates

Cite this: RSC Adv., 2018, 8, 37451

Received 30th August 2018

Accepted 20th October 2018

DOI: $10.1039 / c 8 r a 07251 e$

rsc.li/rsc-advances

\section{Isolation and evaluation of two angiotensin-I- converting enzyme inhibitory peptides from fermented grains (Jiupei) used in Chinese Baijiu production}

\author{
Limo Zhang, $\dagger^{\mathrm{a}}$ Yunsong Jiang, $\dagger^{\mathrm{b}}$ Zhongtian Yin, ${ }^{\mathrm{b}}$ Jinyuan Sun, $\mathbb{D}$ *ab Hehe $\mathrm{Li}^{\text {ab }}$ \\ Xiaotao Sun, ${ }^{\mathrm{ab}}$ Mingquan Huang (D) ab and Fuping Zheng ${ }^{\mathrm{ab}}$
}

In the present study, fermented grains (Jiupei), the raw material for Baijiu distillation, were used to isolate and identify low molecular weight peptides with angiotensin-l-converting enzyme (ACE) inhibitory activities. The methods of peptides extraction from Jiupei are described as follows: ultrasonication, centrifugation and filtration. Peptide purification was performed by ultrafiltration, adsorption on a macroporous resin, gel chromatography and reversed-phase high-performance liquid chromatography (RP-HPLC). HPLC with quadrupole-time-of-flight-mass spectrometry/mass spectrometry (HPLC-QTOF-MS/MS) was used to identify the peptides, and the ACE inhibitory activities of the peptides were measured. Finally, the optimum peptide extraction and separation parameters were determined to be a liquid/solid (ultrapure water/Jiupei powder) ratio of $15 \mathrm{~mL} \mathrm{~g}^{-1}$, extraction temperature of $57{ }^{\circ} \mathrm{C}$ and ultrasonication time of $33 \mathrm{~min}$. XAD-16 resin was used for the removal of sugars and salts. Under these conditions, the total yield of peptides extracted was $57.682 \mathrm{mg} / 1 \mathrm{~g}$ Jiupei. The peptides identified were Val-Asn-Pro and Tyr-Gly-Asp. Val-Asn-Pro exhibited some ACE inhibitory activity $\left(\mathrm{IC}_{50}=38.02 \mu \mathrm{M}\right)$, while Tyr-Gly-Asp showed higher ACE inhibitory activity $\left(\mathrm{IC}_{50}=5.21 \mu \mathrm{M}\right)$. These results provide an important foundation for the study of peptides in Jiupei and show a reference for the trace of peptides in Baijiu production.

\section{Introduction}

Baijiu is the national spirit of China with a long history and is attracting increasing attention around the world due to its unique taste as well as its potential beneficial health effects on humans. ${ }^{1}$ Baijiu is produced by a solid-state fermentation (SSF) process along with a solid-state distillation process. High contents of carbohydrates and certain proteins and tannins are needed for the adsorption and utilization of microorganisms in the raw materials during the fermentation stage of Baijiu. ${ }^{2}$ Jiupei is the main raw material for producing Baijiu. To make Jiupei, some cereals with starch and sugar such as sorghum alone or a mixture of rice, corn, peas, millet and sorghum are steamed, cooled, and then mixed with Jiuqu, which is a fermentation starter that can improve Baijiu's flavor. ${ }^{1}$ The mixture will then be put in an underground fermentation pit for a certain period of time and this fermented mixture is called

\footnotetext{
${ }^{a}$ Beijing Laboratory for Food Quality and Safety, Beijing Technology \& Business University (BTBU), Beijing 100048, PR China.E-mail: sunjinyuan@btbu.edu.cn ${ }^{b}$ Beijing Advanced Innovation Center for Food Nutrition and Human Health, Beijing Technology \& Business University (BTBU), Beijing 100048, PR China

$\dagger$ Limo Zhang and Yunsong Jiang contributed equally.
}

Jiupei. Finally, Jiupei will be taken out and distilled under solidstate conditions to produce fresh Baijiu. The production flow diagram of Jiupei is shown in Fig. 1.

In today's world, drinking is not only about taste, flavor and enjoyment. Consumers also want to drink healthily. Therefore, the health benefit aspects of alcoholic beverages have caused increasing concerns for people. Baijiu has long been used as a base for traditional Chinese medicine since ancient times, and moderate consumption of Baijiu is also considered to be beneficial to human health from the perspective of modern medicine. ${ }^{3}$ Some papers have been published on the health factors in Baijiu, ${ }^{\mathbf{4} 5}$ such as acids, phenolic compounds, and pyrazines. Numerous flavor compounds are generated during the special fermentation and distillation process for making Baijiu. ${ }^{6}$ In addition to ethanol and water, many volatile compounds will be steamed out along with some non-volatile compounds in trace levels. It is also probable that peptides with bioactivities will enter into Baijiu through the distillation process.

Peptides are the functional fragments of proteins, while amino acids are the basic building blocks of peptides. ${ }^{7}$ In vivo, proteins are transformed into the free forms of amino acids and low molecular weight peptides by enzymatic hydrolysis, 


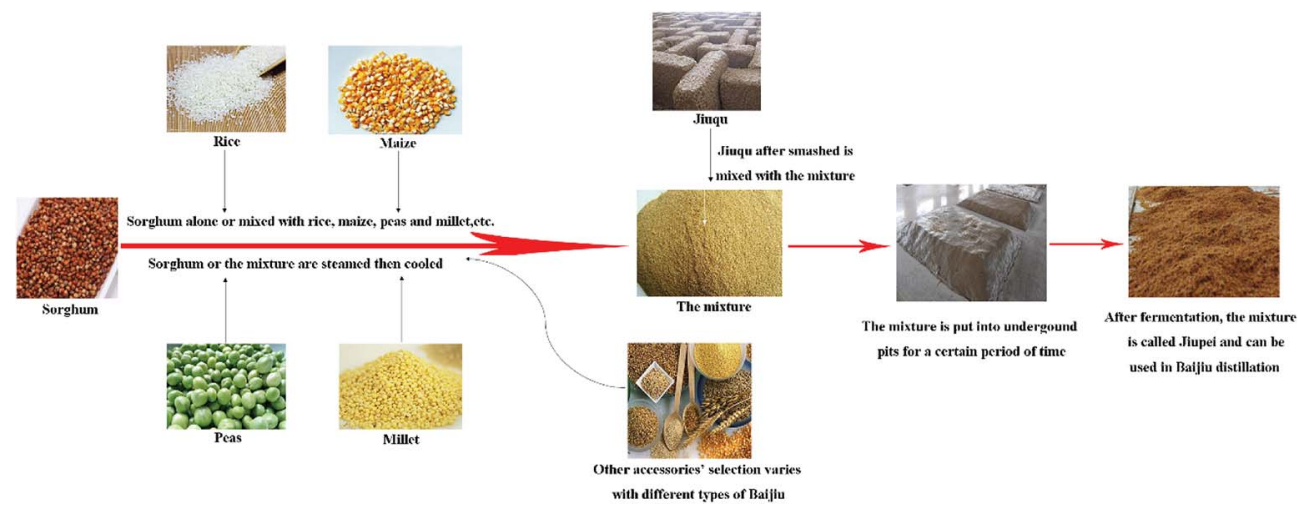

Fig. 1 The production flow diagram of Jiupei.

and then are absorbed by the human body. ${ }^{8}$ Peptides have extremely important roles in the cellular activity and functional properties for human life. ${ }^{9,10}$ Peptides can be depleted in the body because of various factors, and if the ability to synthesize peptides is greatly reduced, human health will be affected. Peptides can act as antioxidants, ${ }^{11}$ prevent cell degeneration, ${ }^{12}$ and possess antibacterial activity $;{ }^{13}$ also, some peptides are antihypertensives. ${ }^{14}$

The function of peptides as antihypertensives is of interest because hypertension is a very prevalent disease and the increasing incidences of hypertension is a healthcare problem worldwide. ${ }^{14}$ Angiotensin-I-converting enzyme (ACE) plays an important role in blood pressure regulation in vivo. ACE is a zinc peptidase enzyme that can be activated by many substrates in the human body. ACE hydrolyzes angiotensin I into angiotensin II and causes degradation of bradykinin and vasoconstriction, which are the main causes of hypertension in the reninangiotensin system (RAS) and kallikrein-kinin system (KKS). The antihypertensive abilities of peptides can be evaluated using the half maximal inhibitory concentration $\left(\mathrm{IC}_{50}\right){ }^{15}$ Peptide inhibition of ACE occurs in a similar manner to the action of other antihypertensive drugs. Techniques for the extraction and separation of peptides with ACE inhibitory activity have reached maturity gradually.

Hypertension can be led by ACE, ${ }^{15}$ and the ACE inhibitory peptides that can reduce blood pressure are of interest in the food and beverage industry. ${ }^{16}$ An inhibitory peptide NMAINPSKENLCSTFCK, with an $\mathrm{IC}_{50}$ value $129.07 \mu \mathrm{M}$, derived from the as2-casein fragment residues $25-41$, was screened and identified by ultra-performance liquid chromatography-electron spray ionization with quadrupole-time-of-flight-mass spectrometry/ mass spectrometry (UPLC-ESI-Q-TOF-MS/MS) from tryptic casein hydrolysate ${ }^{17}$ Moayedi et al. ${ }^{18}$ found that a hexapeptide DGVVYY with a $\mathrm{IC}_{50}$ value $2 \mu \mathrm{M}$, derived from tomato waste protein, had the capability to restrain the functioning of ACE.

The bioactivities and functions, particularly the ACE inhibitory function of polypeptides in Baijiu are of interest. To date, a tripeptide with ACE inhibitory activity has been isolated from Guojing sesame flavor-type Baijiu by a direct concentration method and high performance liquid chromatography (HPLC)ESI-Q-TOF-MS. ${ }^{19}$ A tetrapeptide Ala-Lys-Arg-Lla has also been identified by HPLC-Q-TOF-MS, which showed protection of HepG2 cells and prevention of a large decrease in oxidized glutathione (GSSG), superoxide dismutase (SOD) and catalase (CAT) levels induced by AAPH. ${ }^{20}$ These previous studies have provided an understanding of the types and functions of some of the polypeptides in Baijiu. Theoretically speaking, there are more non-volatile compounds in Jiupei that have not been distilled in the final Baijiu product. Jiupei could be a better object for the study on the polypeptides considering the high protein content of raw materials. However, few investigations on this subject have been reported.

The main objective of this study was to optimize the conditions for the extraction, separation, and purification of peptides from Jiupei for their identification. The total flow chart of peptide extraction, purification and identification is shown in Fig. 2. We also evaluated the ACE inhibitory potentials of the peptides and calculated their $\mathrm{IC}_{50}$ values.

\section{Materials and methods}

\subsection{Chemicals and reagents}

Jiupei (water content $64 \%$, sugar content $1.2 \%$, lipid content $3.45 \%$, other content $31.35 \%$ ) of Guojing sesame flavor-type Baijiu was kindly provided by the Bandaojing Liquor Co. Ltd. (Zibo, China). Chromatography grade hexane, acetonitrile and anhydrous ethanol were purchased from Thermo Fisher Scientific (Shanghai, China). Val-Asn-Pro and Tyr-Gly-Asp standards (purity $>98 \%$ ) were purchased from Shanghai Gil Biological Science and Technology Co. Ltd (Shanghai, China). Trifluoroacetic acid (TFA) and formic acid were purchased from Merck (Darmstadt, Germany). Chloroacetic acid was obtained from Aladdin Shanghai Biochemical Technology Co. Ltd (Shanghai, China). Bovine serum albumin, total protein biuret reagent set, hippuryl-histidyl-leucine, hippuric acid (purity > 99\%) and borate buffer ( $\mathrm{pH}$ 8.3) were purchased from Shanghai Source Leaf Biotechnology Co. Ltd (Shanghai, China). ACE derived from rabbit lungs was purchased from Sigma-Aldrich Chemie GmbH (Munich, Germany). Distilled water was provided by Milli-Q system (Millipore, Bedford, USA). Ultrapure water was obtained from Hangzhou Wahaha Corporation (Hangzhou, China). All reagents and chemicals were of HPLC grade. 

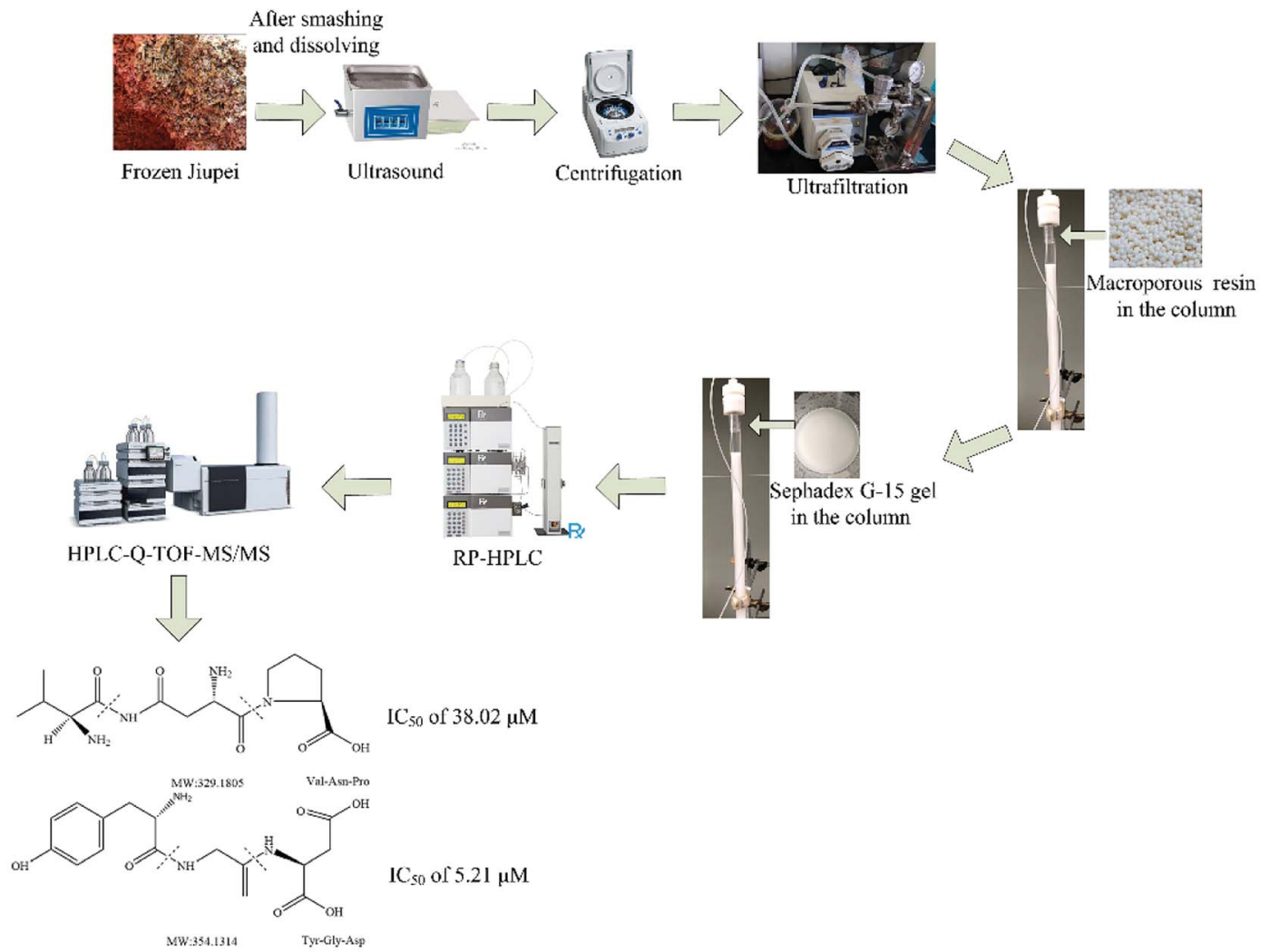

Fig. 2 Total flow chart of peptides extraction, purification and identification.

Table 1 Details for the three macroporous resins used in the adsorption experiments

\begin{tabular}{llllr}
\hline Number & Resin model & Surface characteristics & Polarity & \multicolumn{1}{c}{$\begin{array}{l}\text { Specific area } \\
\left(\mathrm{m}^{2} \mathrm{~g}^{-1}\right)\end{array}$} \\
\hline 1 & DA201-C & Brown globular & Nonpolar & $1000-1300$ \\
2 & AB-8 & White globular & Low polar & $480-520$ \\
3 & XAD-16 & White & Nonpolar & 800 \\
pore size
\end{tabular}

\subsection{Instrument and equipment}

A Pellicon ultrafiltration unit was purchased from Merck Millipore (Darmstadt, Germany). An automatic LC separation device (MB 99-2) was obtained from the Shanghai Qingpu West Instrument Factory (Shanghai, China). HPLC-Q-TOF-MS/MS (HPLC model 1290, Q-TOF model 6530) was purchased from Agilent Technologies (Santa Clara City, USA). Two XBridge peptide $\mathrm{BEH} \mathrm{C}_{18}$ reversed-phase (RP) chromatographic columns $(150 \mathrm{~mm} \times 4.6 \mathrm{~mm}, 5 \mathrm{~m} ; 150 \mathrm{~mm} \times 10 \mathrm{~mm}, 5 \mathrm{~m})$ were obtained from Waters (Wexford, Ireland).

\subsection{Extraction of peptides from Jiupei}

Experiments were performed using single factor and central composite designs. Frozen Jiupei (400 g) was weighed, dried at $40{ }^{\circ} \mathrm{C}$ to a constant mass, and then crushed between 40 mesh screens. Ultrapure water (ultrapure water/Jiupei powder ratio of $15 \mathrm{~mL} \mathrm{~g}^{-1}, \mathrm{pH}$ 9.0) was added into the Jiupei powder and the mixture was stirred using a magnetic stirrer at $57^{\circ} \mathrm{C}$ for $1 \mathrm{~h}$. The mixture was then extracted by ultrasonication for $33 \mathrm{~min}$, centrifuged $\left(4{ }^{\circ} \mathrm{C}, 4900 \times g\right)$ several times and then, the supernatant was retained. The supernatant was mixed with pure hexane (volume ratio, supernatant : hexane $=1: 5$ ) to defat for $3 \mathrm{~h}$. Then, the defatted supernatant was filtered by a vacuum filter, following which the filtrate was collected. A water-soluble extract concentrate from the filtrate was obtained after concentration for $1 \mathrm{~h}$ under vacuum $\left(0.09 \mathrm{MPa}, 50{ }^{\circ} \mathrm{C}\right)$. The peptide content was determined by the Biuret method, ${ }^{21}$ for which bovine serum albumin was used as a standard.

\subsection{Ultrafiltration}

A $5 \mathrm{kDa}$ ultrafiltration membrane in a Pellicon ultrafiltration device was used for the ultrafiltration of the Jiupei water soluble extract concentrate at room temperature and 0.05 MPa. Two fractions (molecular weight $>5 \mathrm{kDa}$ and $<5 \mathrm{kDa}$ ) were obtained. Bioactive peptides usually have molecular weights $<5 \mathrm{kDa},{ }^{22}$ so 
the $<5 \mathrm{kDa}$ fraction was condensed to $50 \mathrm{~mL}$ with a concentration of $10 \mathrm{mg} \mathrm{mL}^{-1}$ at $50{ }^{\circ} \mathrm{C}$ and $0.09 \mathrm{MPa}$ under vacuum. The condensed sample was kept in a sealed conical flask at $4{ }^{\circ} \mathrm{C}$ in a refrigerator.

\subsection{Extraction of peptides from the Jiupei concentrate by adsorption on macroporous resin}

Three types of macroporous resins with different polarities, specific surface areas and average pore sizes were studied (Table 1). The three resins were compared, and the resin that provided the best results for peptide adsorption plus sugar and salt elimination was selected for further use. Resin (10 g) and Jiupei concentrate $\left(50 \mathrm{~mL}, 10 \mathrm{mg} \mathrm{mL}{ }^{-1}\right)$ were mixed together. The mixture was placed in a constant temperature $\left(25^{\circ} \mathrm{C}\right)$ water bath and vibrated for $24 \mathrm{~h}$. During this process, samples were collected at 20,40,60, 120, 180 and $240 \mathrm{~min}$. The peptide contents and adsorption rates on the three macroporous resins were calculated by the Biuret method using the following formula: absorbance of the eluate that came out of the column was monitored at $220 \mathrm{~nm}$ using a UV detector. Eluate fractions from the column were collected, and those that contained the same component were combined and freeze-dried to obtain powder of peptides with different molecular weights.

\subsection{Semi preparative RP-HPLC separation and purification of the Jiupei peptides}

Because of the high requirements of sample purity for structural identification, the Jiupei peptides obtained by gel filtration chromatography were purified further. First, ultrapure water was used to prepare a $5 \mathrm{mg} \mathrm{mL} \mathrm{mL}^{-1}$ sample solution of each peptide powder. Then, each solution was manually filtered through a $0.45 \mu \mathrm{m}$-filter syringe. HPLC separation was performed using an Xbridge Peptide $\mathrm{BEH} \mathrm{C}_{18}$ column $(150 \mathrm{~mm} \times$ $10 \mathrm{~mm}, 5 \mu \mathrm{m}$ ) with a mixture of $0.1 \%$ formic acid in ultrapure water (A) and $0.1 \%$ formic acid in acetonitrile (B) as the mobile phase. The gradient elution was performed as follows: 0$40 \mathrm{~min}, 5-60 \% \mathrm{~B}$; $40-45 \mathrm{~min}, 60-5 \% \mathrm{~B}$; and $45-50 \mathrm{~min}, 5 \% \mathrm{~B}$. The injection volume was $1 \mathrm{~mL}$ and the column temperature was $30^{\circ} \mathrm{C}$. The mobile phase flow rate was $5 \mathrm{~mL} \mathrm{~min}^{-1}$ and the

$$
\text { Adsorption rate }(\%)=\frac{\text { total peptides concentration }- \text { concentration after adsorption }}{\text { total peptides concentration }} \times 100 \% \text {. }
$$

The resin with the best absorption efficiency (XAD-16) was selected for further use. XAD-16 resin was loaded in a chromatographic column (ø $2.6 \mathrm{~cm}$, length $60 \mathrm{~cm}$ ), and $100 \mathrm{~mL}$ of the sample was added to it. Then, the column was rinsed with ultrapure water at a flow rate of $2 \mathrm{~mL} \mathrm{~min}^{-1}$ to remove any nonabsorbed matter. The sample that was added to the column was collected periodically during this process. The sugar content of the concentrate was measured by the phenol sulfuric acid method. ${ }^{23}$ When the sugar content was removed, the column was eluted with $40 \%$ ethanol at a flow rate of $1.5 \mathrm{~mL} \mathrm{~min}^{-1}$. The absorbance of the sample was monitored at $220 \mathrm{~nm}$ using an ultraviolet (UV) detector. Fractions of the sample were collected in $50 \mathrm{~mL}$-tubes and those components belonging to the same cluster, according to the UV detector results, were combined. Each combined fraction that was free of sugars and salts was concentrated under vacuum and then freeze-dried.

\subsection{Separation and purification of the Jiupei peptides by gel filtration chromatography}

The compositions of the Jiupei peptides obtained by the macroporous resins were complex. Therefore, further purification was performed using the differences in the molecular weights of the components. First, each frozen Jiupei peptide sample was dissolved in $5 \mathrm{~mL}$ ultrapure water. Then, Sephadex G-15 gel was loaded in a chromatographic column (ø 1.6, length $70 \mathrm{~cm})$ and $4 \mathrm{~mL}$ of each Jiupei peptide solution, made in the first step, was added into the column. Next, the column was rinsed with ultrapure water at a flow rate of $0.5 \mathrm{~mL} \mathrm{~min}^{-1}$ and the detection wavelength was $214 \mathrm{~nm}$. Fractions of the eluate were collected, and those containing the same component were combined. Acetonitrile and formic acid were removed from the combined fractions using a rotary evaporator, and the resulting residues were freeze-dried for further use.

\subsection{Determination of the Jiupei peptides purity}

The as-prepared peptide powders were dissolved in ultrapure water, filtered through $0.45 \mu \mathrm{m}$-syringe filters, and then analyzed by HPLC (1260, Agilent). HPLC separation was performed using a Xbridge Peptide $\mathrm{BEH} \mathrm{C}_{18}$ column $(150 \mathrm{~mm} \times$ $4.6 \mathrm{~mm} ; 5 \mu \mathrm{m})$. The mobile phase was a mixture of ultrapure water containing $0.05 \%$ TFA (A) and acetonitrile containing $0.05 \%$ TFA (B). The following mobile phase gradient was used: 0-40 min, 5-60\% B; 40-40.5 min, 60-100\% B; 40.5-45 min, $100 \% \mathrm{~B}$; $45-45.5 \mathrm{~min}, 100-5 \% \mathrm{~B}$; and $45.5-50 \mathrm{~min}, 5 \% \mathrm{~B}$. The

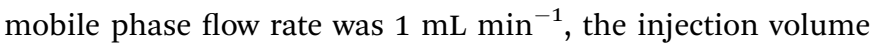
was $10 \mu \mathrm{L}$, the column temperature was $30^{\circ} \mathrm{C}$ and the detection wavelength was $214 \mathrm{~nm}$.

\subsection{Determination of the peptides sequences by HPLC-Q- TOF-MS/MS}

Each purified peptide solution was identified by HPLC-Q-TOFMS/MS (HPLC model 1290, Q-TOF model 6530, Agilent Technologies). HPLC separation was performed using a Xbridge Peptide $\mathrm{BEH} \mathrm{C}_{18}$ column $(150 \mathrm{~mm} \times 10 \mathrm{~mm}, 5 \mu \mathrm{m})$. The mobile phase was a mixture of ultrapure water containing $0.1 \%$ formic 
acid (A) and acetonitrile containing $0.1 \%$ formic acid (B). The following gradient elution was the same as described before, with the semi preparative RP-HPLC. The mobile phase flow rate was $0.5 \mathrm{~mL} \mathrm{~min}^{-1}$, the injection volume was $5 \mu \mathrm{L}$, the column temperature was $30{ }^{\circ} \mathrm{C}$, and the detection wavelength was $214 \mathrm{~nm}$. TOF MS was operated with an ESI source in positive ionization mode. The scan mode was normal, the scan range was $m / z=50-1500$, the dry gas temperature was $350{ }^{\circ} \mathrm{C}$, the sheath gas temperature was $350{ }^{\circ} \mathrm{C}$, the spray needle pressure was $241.325 \mathrm{kPa}$, the capillary voltage was $4000 \mathrm{~V}$, the splitting voltage was $175 \mathrm{~V}$ and the collision cell voltage was $10 \mathrm{~V}$. A de novo sequencing algorithm was used to analyze the fragmentation information from each ion. Data were collected and analyzed on a Mass Hunter B.06.00 computer workstation (Agilent Technologies).

\subsection{In vitro evaluation of peptides ACE inhibitory activities}

The ACE inhibitory activities of the peptides were measured using HPLC following an established $\operatorname{method}^{\mathbf{1 9}}$ with minor modifications. The content of hippuric acid, produced by hydrolysis of leucine, was used to measure the inhibitory activity of the peptides. ${ }^{24}$ Peptide standard solutions with concentrations of $40 \mu \mathrm{M}, 20 \mu \mathrm{M}, 10 \mu \mathrm{M}, 5 \mu \mathrm{M}$ and $2.5 \mu \mathrm{M}$ were prepared with a borate-boric acid buffer $(100 \mu \mathrm{M}, \mathrm{pH} 8.3)$. The inhibitor concentration and inhibition rate curves were used to measure the $\mathrm{IC}_{50}$ value, which represents the concentration of peptides and hydrolysates required for 50\% inhibition of ACE.

\section{Results}

\subsection{Optimization of peptides extraction conditions for Jiupei}

The effects of ultrasonication time $\left(X_{1}\right)$, extraction temperature $\left(X_{2}\right)$ and liquid/solid (ultrapure water/Jiupei powder) ratio $\left(X_{3}\right)$ on the peptide yield were investigated using a single factor test. We used response surface methodology with three factors-three levels and a Box-Behnken design.

The selected factor levels are shown in Table 2(a). The peptide yield was used as the response. The results listed in Table 2(b) were obtained by multivariate regression fitting with Design Expert (version 7.0).

$$
\begin{aligned}
Y & =-166.98113+2.38239 X_{1}+8.14340 X_{2}+4.24151 X_{3} \\
& +0.01157 X_{1} X_{2}-0.01635 X_{1} X_{3}-0.00981 X_{2} X_{3}-0.02474 X_{1}{ }^{2} \\
& -0.25887 X_{2}{ }^{2}-0.03076 X_{3}{ }^{2}
\end{aligned}
$$

Variance analysis of the regression model (Table 3) gave a $p$ value of 0.0057 , and the equation had significant difference ( $p$ $<0.05$ ), which showed that the relationship between the factors and response could be described by the regression equation. There were good linear relationships between the

Table 2 The factors and levels in Box-Behnken design (BBD) (a). BBD and the responses for peptides yield of Jiupei (b)

(a)

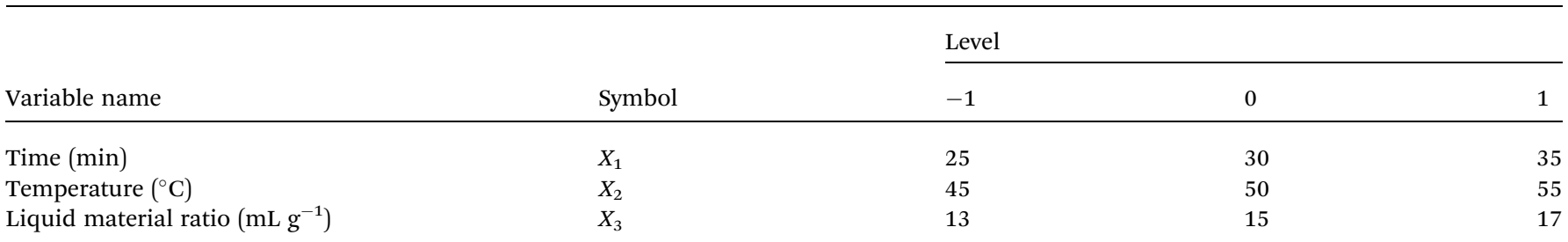

(b)

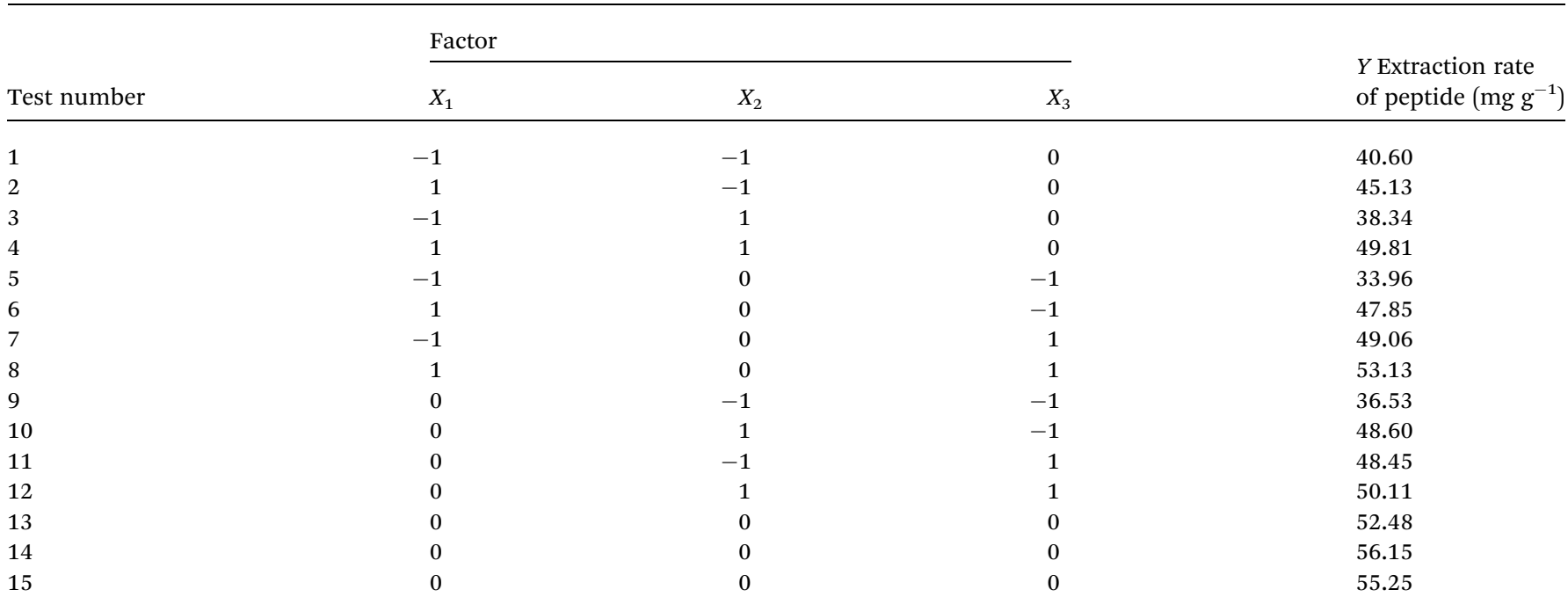


Table 3 ANOVA of peptide yield from the Box-Behnken experiment

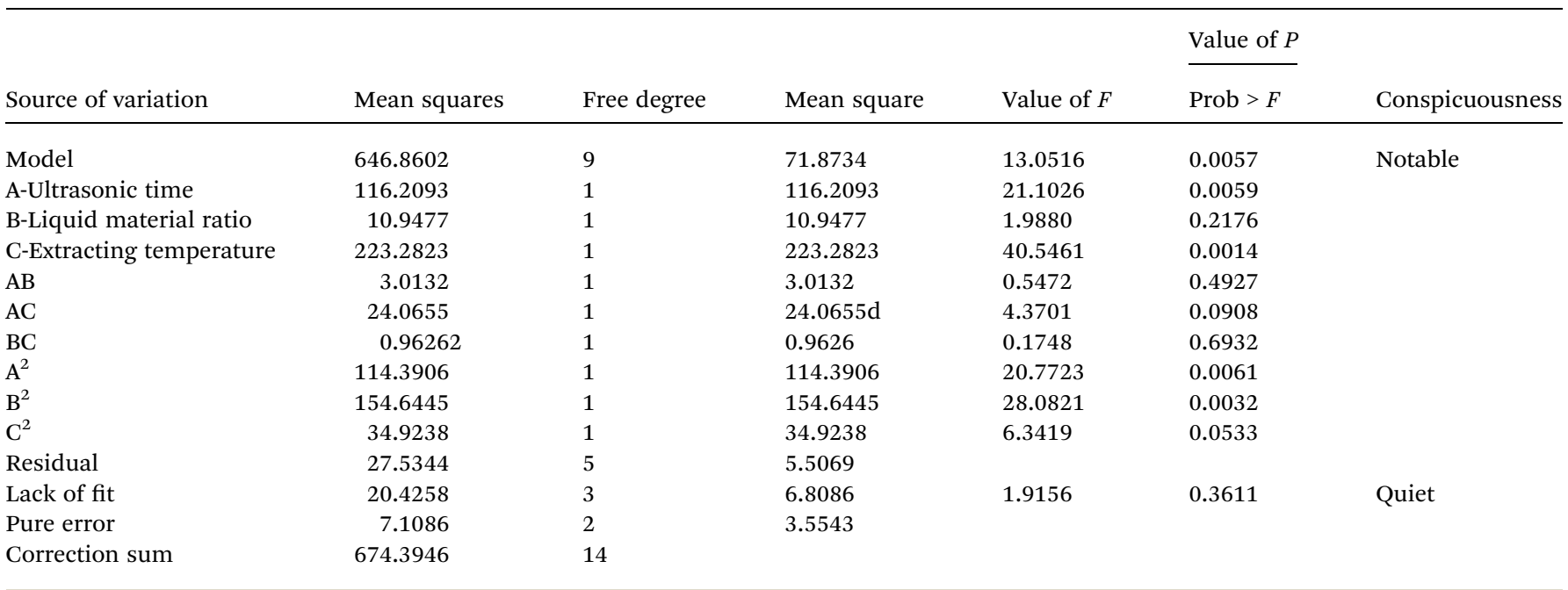

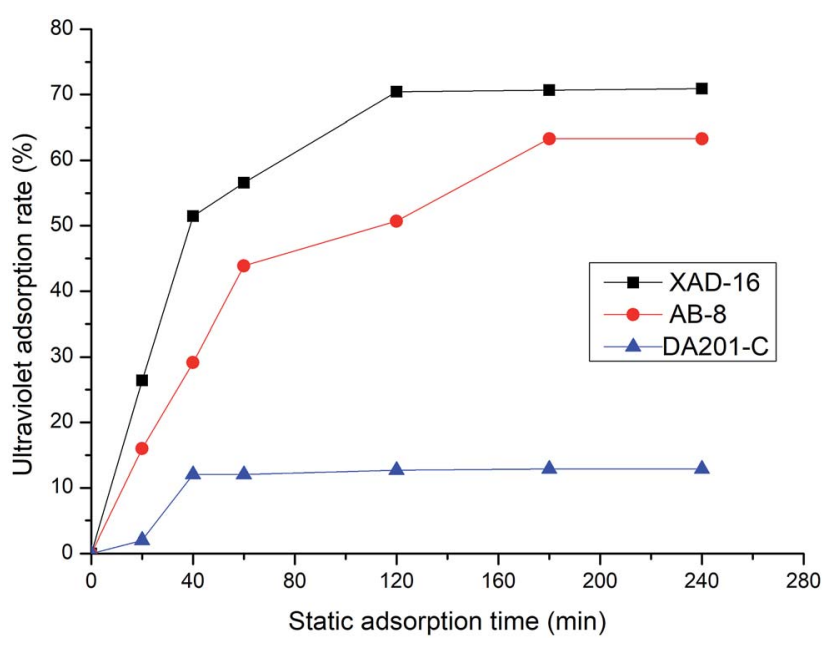

Fig. 3 Adsorption ratio of the peptides absorbed on different resins (DA201-C, AB-8 and XAD-16).

dependent variable and all independent variables, which showed that the test method was reliable. The lack-of-fit was $0.3611(>0.05)$, and there was no notable difference between the two items where the equation was good for the test. The experimental error was small $\left(R^{2}=0.9592\right)$, which showed that the equation was fitted well.

Optimization of the Jiupei peptide extraction conditions was performed according to the regression equation. The optimized conditions were an ultrasonication time of $33 \mathrm{~min}$, liquid/solid (ultrapure water/Jiupei powder) ratio of $15 \mathrm{~mL} \mathrm{~g}^{-1}$ and extraction temperature of $57^{\circ} \mathrm{C}$. The final yield of Jiupei peptides was $57.682 \mathrm{mg} / 1 \mathrm{~g}$ Jiupei.

\subsection{Screening of macroporous resins in static adsorption experiments}

To select the type of macroporous resin to remove sugars and salts from the extract, three macroporous adsorption resins (XAD-16, AB-8 and DA201-C) were evaluated for their static adsorption rates. The adsorption results of each resin are shown in Fig. 3. The XAD-16 resin had the highest static adsorption rate $(70.93 \%)$ among the resins and took a relatively short time to reach the maximum adsorption rate. Therefore, the XAD-16 resin was selected as the most suitable resin for purification of the Jiupei extract. The sample was separated using the XAD-

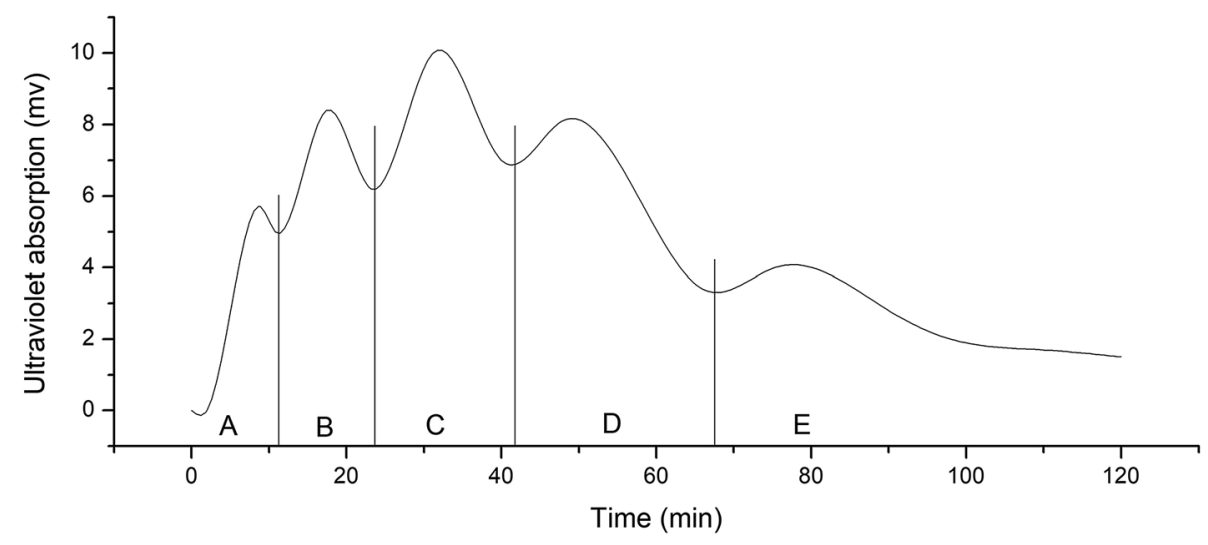

Fig. 4 Gel permeation chromatogram of the fractions. 
(a)

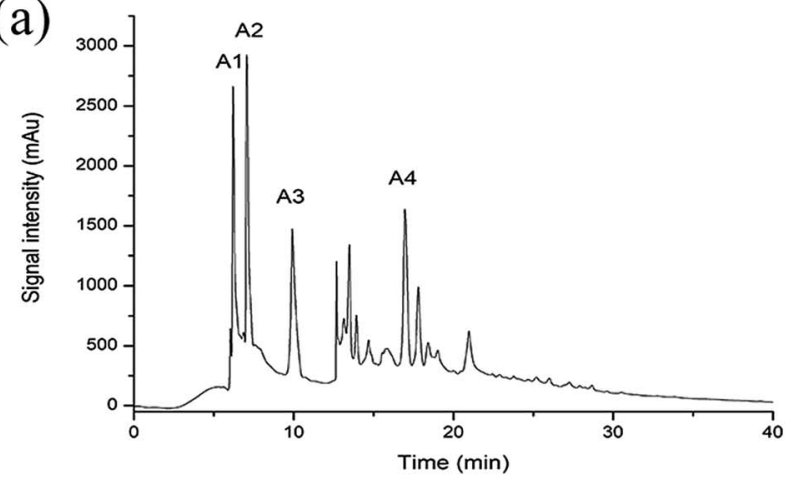

(c)

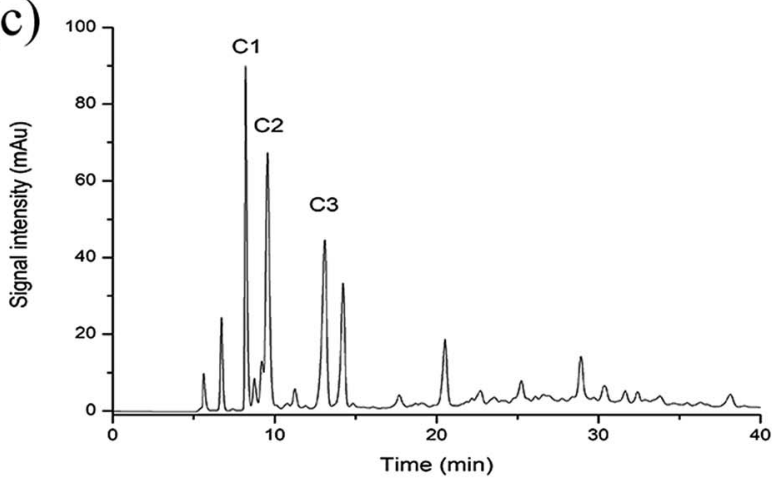

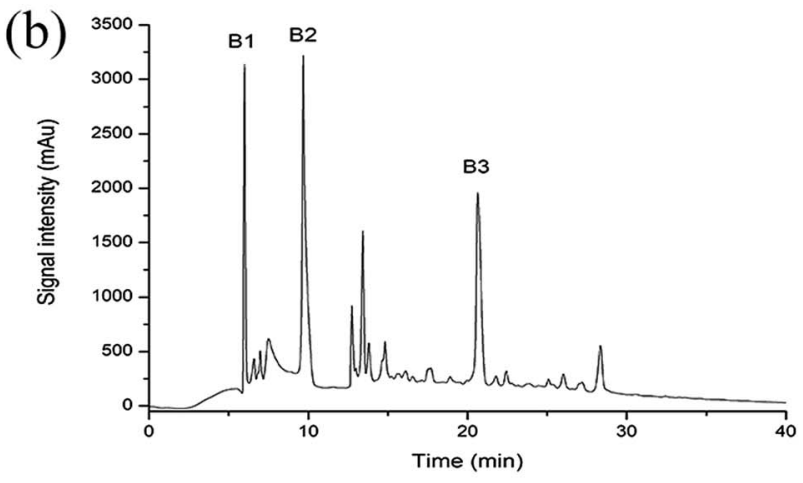

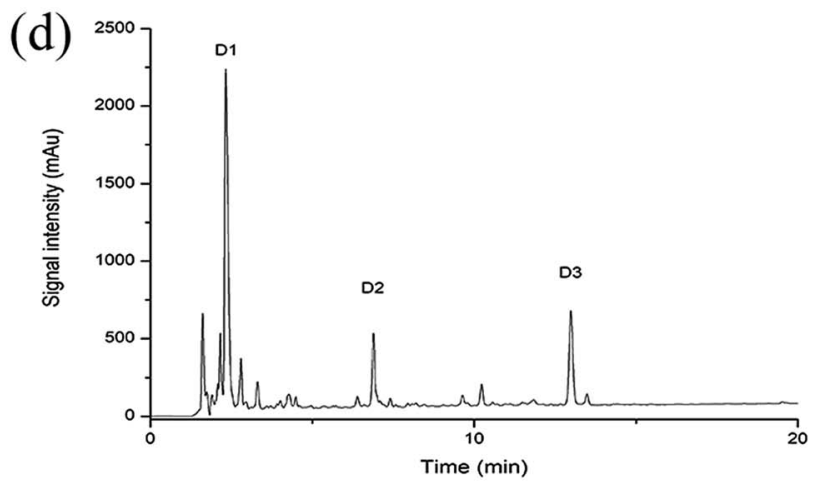

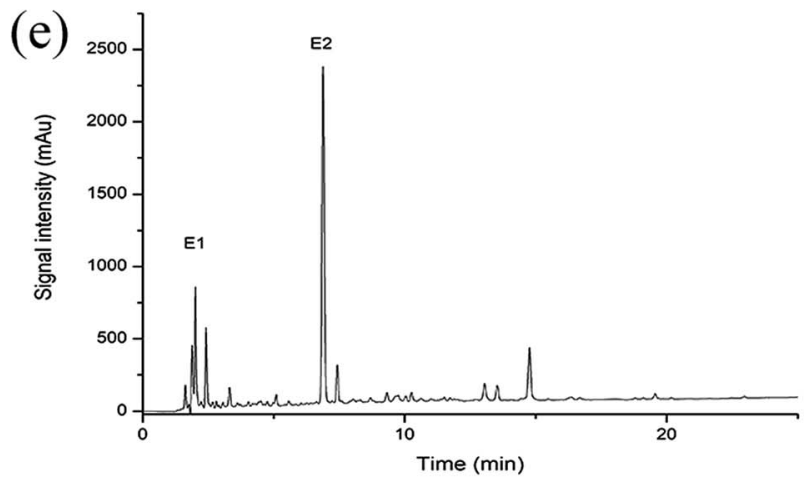

Fig. 5 RP-HPLC chromatogram of fractions A, B, C, D, and E.

16 resin. Subsequently, $40 \%$ ethanol was used for desorption. Consequently, the peak was evidently observed and the eluent consumption was low.

\subsection{Separation and purification of Jiupei peptides by gel filtration chromatography}

After removal of the sugars and salts by the XAD-16 resin, the extract was subjected to gel filtration chromatography and five fractions (A-E) were collected. Gel filtration chromatography separated some of the peptides in the Jiupei extract (Fig. 4). However, the composition of each fraction was still complex after this separation. Some fractions had multiple components, which would make it difficult to identify the peptides. Therefore, further purification of the fractions obtained by gel chromatography was performed.

\subsection{Separation and purification of peptides in Jiupei by} semi-preparative RP-HPLC

The five fractions (A-E) separated by gel chromatography were further separated by semi-preparative RP-HPLC. Fractions containing high resolution and strong signals were retained. Four subfractions (A1-A4) were collected from fraction A, three (B1-B3) from fraction $B$, three (C1-C3) from fraction $C$, three (D1-D3) from fraction D and two (E1 and E2) from fraction $E$ (Fig. 5).

\subsection{Analysis of the Jiupei peptides purity}

Purity analysis of the separated subfractions was performed on an Agilent 1260 HPLC system. Among the subfractions, D1 and E1 showed strong signals (Fig. 6). Therefore, D1 and E1 were selected for subsequent experiments. Clear peaks were observed and the separation had removed the background peaks. 

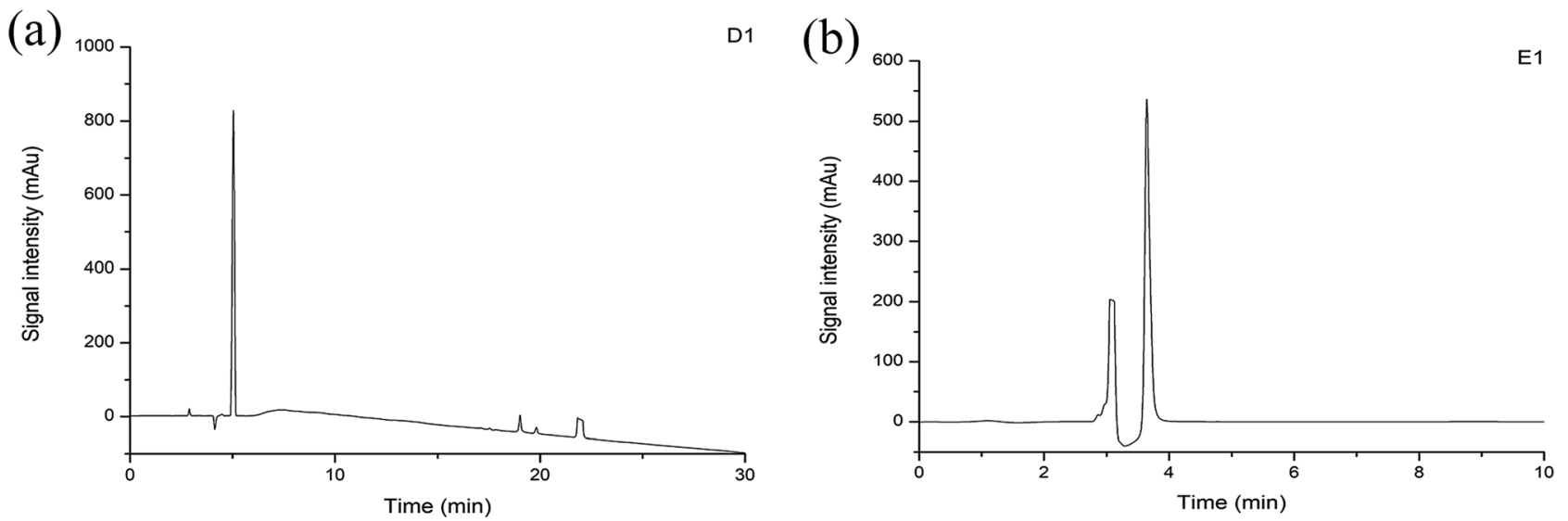

Fig. 6 The chromatogram for purity analysis of the fraction (a) D1 and (b) E1.

(a)

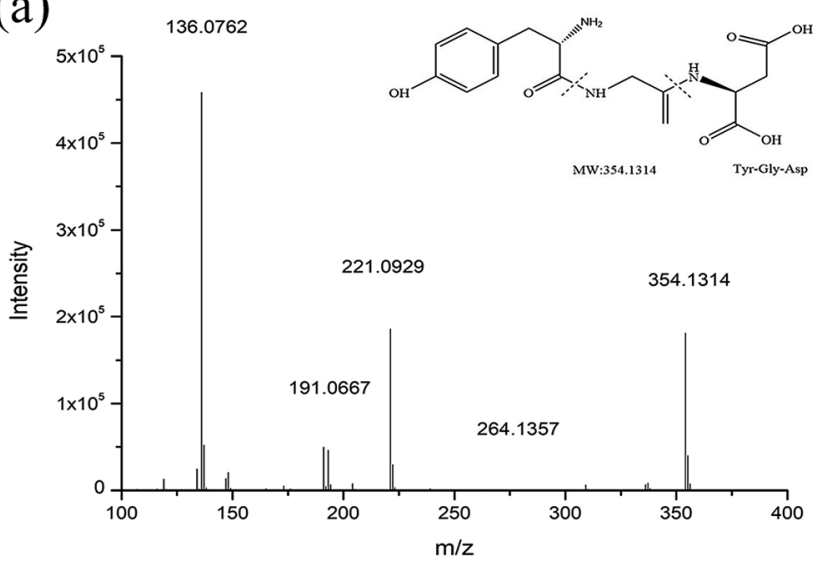

(b)

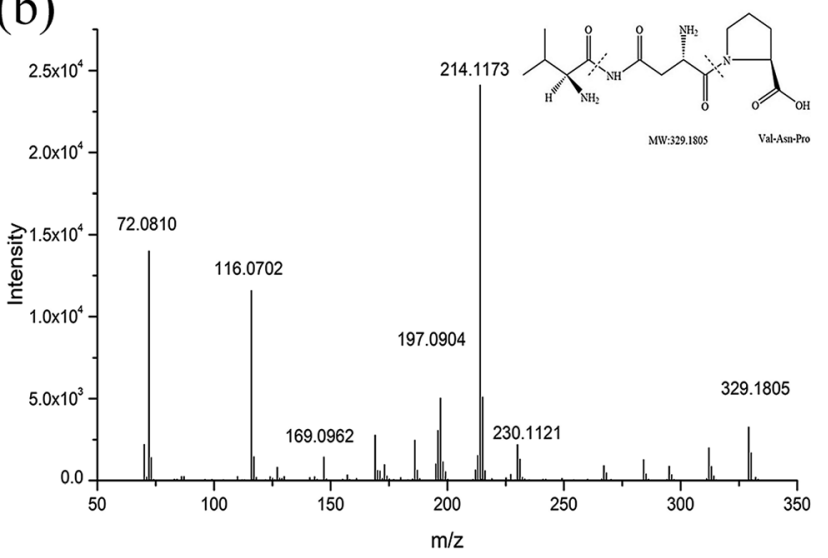

Fig. 7 Mass/mass spectra of D1 ( $\mathrm{m} / \mathrm{z}=354.1314)$ and collision-induced fragment of $\mathrm{m} / \mathrm{z} 354.1314$. Mass $/ \mathrm{mass}$ spectra of E1 $(\mathrm{m} / \mathrm{z}=329.1805)$ and collision-induced fragment of $\mathrm{m} / \mathrm{z} 329.1805$.

Therefore, these subfractions could be used for identification of the peptides.

\subsection{Determination of the peptides sequences by HPLC-Q- TOF-MS/MS}

The peptides were qualitatively analyzed as follows using the standard method reported by Toelstede ${ }^{25}$ et al. The mass spectrum of subfraction D1 showed a peak with $\mathrm{m} / \mathrm{z}=354.1314$ at $4.725 \mathrm{~min}$. In the MS/MS spectrum (Fig. 7), we speculated that the $m / z=221.0929$ peak was for a $b_{2}$ ion (probably Tyr-Gly), the $m / z=191.0667$ peak was for a $y_{2}$ ion (probably Gly-Asp) and the $m / z=136.0762$ peak was for an $\mathrm{a}_{1}$ ion (probably Tyr). Based on these results, we concluded that the amino acid sequence of the peptide with $m / z=354.1314$ was Tyr-Gly-Asp. Similarly, the mass spectrum of subfraction E1 showed a peak at $5.115 \mathrm{~min}$ with $m / z=329.1805\left([\mathrm{M}+\mathrm{H}]^{+}\right)$and its molecular formula was $\mathrm{C}_{14} \mathrm{H}_{24} \mathrm{~N}_{4} \mathrm{O}_{5}$. The MS/MS of the parent ion at $m / z=329.1805$ was recorded. We speculated that the $m / z=230.1121$ peak was for $\mathrm{a}_{2}$ ion (probably Asn-Pro), the $m / z=214.1173$ peak was for $\mathrm{a} \mathrm{b}_{2}$ ion (probably Val-Asn), the $m / z=116.0702$ peak was for a $y_{1}$ ion (probably Pro) and the $m / z=72.0810$ peak was for an $\mathrm{a}_{1}$ ion (probably Val). Based on this, we concluded that the amino acid sequence of the peptide with $\mathrm{m} / z=329.1805$ was Val-Asn-Pro.

Standards for Tyr-Gly-Asp and Val-Asn-Pro were analyzed under the conditions specified. The retention times and mass spectra of the two fragments were consistent with the fragmentation peaks of the parent ions detailed above. Therefore, the amino acid sequence of the peptide with $\mathrm{m} / \mathrm{z}=354.1314$ in D1 was determined to be Tyr-Gly-Asp and that with $\mathrm{m} / \mathrm{z}=$ 329.1805 in E1 was determined to be Val-Asn-Pro. The structural expressions are shown in Fig. 7.

\subsection{Determination of the ACE IC $_{50}$ of Val-Asn-Pro and Tyr- Gly-Asp}

The inhibitory activity of ACE was measured as described. The $\log$ (ACE inhibitor) was plotted against $\log [R /(1-R)]$ (Fig. 8), the equation of Val-Asn-Pro was $y=1.285 x-2.029$. When $y$ was 0 , the value of $x$ was 1.58. The equation of Tyr-Gly-Asp was $y=$ $1.005 x-0.720$. When $y$ was 0 , the value of $x$ was 0.717 . No previous studies have isolated Val-Asn-Pro and Tyr-Gly-Asp from 
(a) (b)

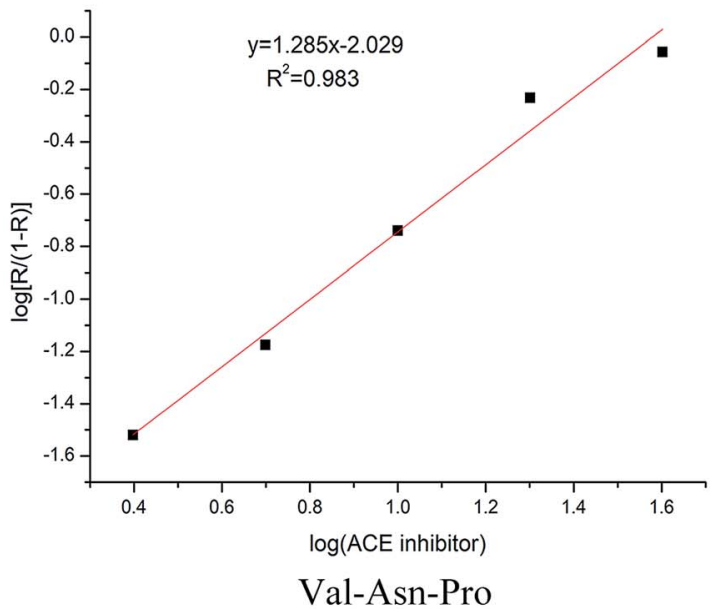

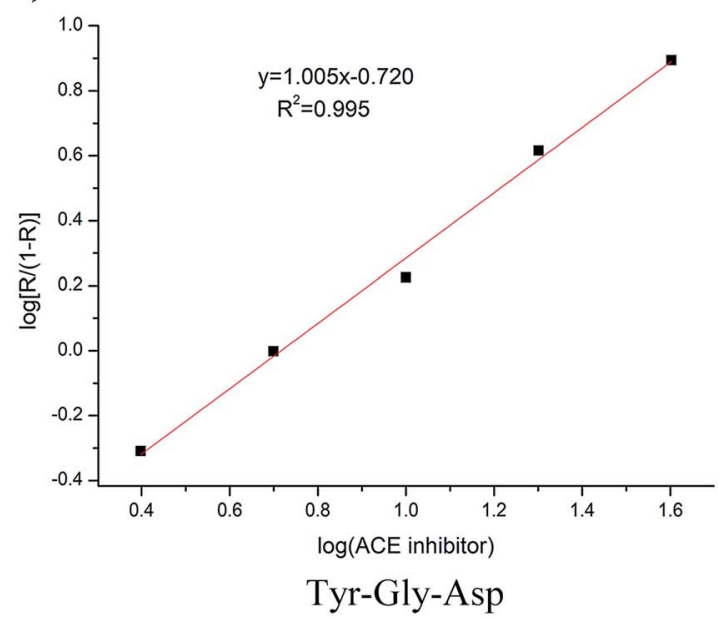

Fig. 8 Inhibition curve of Val-Asn-Pro standard (a). Inhibition curve of Tyr-Gly-Asp standard (b).

Jiupei. Val-Asn-Pro inhibits ACE with an $\mathrm{IC}_{50}$ of $38.02 \mu \mathrm{M}$, while Tyr-Gly-Asp inhibits ACE with an $\mathrm{IC}_{50}$ of $5.21 \mu \mathrm{M}$.

\section{Discussion}

The annual increase in the hypertension incidence has received extensive attention worldwide. The incidence of hypertension in the elderly is higher than that in the young, and this disease is the most widespread in men. ${ }^{26}$ At present, it is an ideal method to treat hypertension with bioactive substances extracted from food or drink. Peptides are a good choice, given their abundance in foods. In the present study, Jiupei of Guojing sesame flavor-type Baijiu was used for the extraction of peptides and the peptide ACE inhibitory activities were investigated.

Proteins can be extracted and purified by a number of methods, including enzymatic hydrolysis extraction, ${ }^{27}$ acid precipitation, ${ }^{28}$ alkaline extraction, ${ }^{29}$ alkaline enzymatic two step extraction, ${ }^{30}$ ultrasound-assisted enzymatic hydrolysis ${ }^{31}$ and the electric membrane method. ${ }^{32}$ Enzyme preparation of polypeptides is cheap, easy and also widely used. However, at the same time, the proteins in the raw materials are degraded or modified by proteases. Alkaline formulations avoid this shortcoming and the experimental operation steps are simple. The main purification methods currently used for peptides are ultrafiltration separation, ${ }^{33}$ macroporous resin adsorption, ${ }^{34}$ gel chromatography ${ }^{35}$ and preparative LC. ${ }^{36}$ The differences in the molecular sizes and polarities of the substances to be separated are used in these methods. Method selection is generally based on characteristics of the target and impurities.

In this study, the extraction temperature, ultrasonication time and liquid/solid (ultrapure water/Jiupei powder) ratio were optimized using a Box-Behnken design. This method avoids combinations with extremes of high or low levels of the factors investigated. Fractionation and purification of ACE peptides from Jiupei required the use of multiple different techniques. Ultrafiltration is often used to separate and concentrate peptides based on its high rate of peptide recovery.
Macroporous resins are important for eliminating sugars and salts from the peptides extract. Sugars are eluted from the resin with distilled water during the elution process. For peptide purification during macroporous resin adsorption, the effect of sugars is relatively larger considering the presence of a certain amount of sugar in the raw material. Therefore, macroporous resin with stronger adsorption with peptides and weaker adsorption with sugars were used during the elution. The effect of salts on the subsequent purification step is relatively small; hence, the anion resin and cation resin were not chosen. ${ }^{37}$

Peptides with molecular weights below $5 \mathrm{kDa}$ are considered to be active with physiological functions, while peptides with molecular weights below $3 \mathrm{kDa}$ exhibit strong free radical scavenging activity and ACE inhibition usually. ${ }^{22}$ Peptides that act as ACE inhibitors generally have relatively low molecular weights. ${ }^{14,38}$ For instance, the ACE inhibitory activity of two 6peptide AYFYFD and LAYFYP ( $\mathrm{IC}_{50}$ value $106 \mu \mathrm{M}$ and $65 \mu \mathrm{M}$ ), two 5-peptide VVLYK and AYFYD ( IC $_{50}$ value $554 \mu \mathrm{M}$ and 1001 $\mu \mathrm{M})^{18}$ are lower than that of Val-Asn-Pro $\left(\mathrm{IC}_{50}\right.$ value $38.02 \mu \mathrm{M}$ ) and Tyr-Gly-Asp ( $\mathrm{IC}_{50}$ value $5.21 \mu \mathrm{M}$ ) identified in this study.

Bioactive peptides that act as ACE inhibitors are found in plants, animals, microorganisms, as well as fungi, and can be extracted from raw materials in hydrolysates. ${ }^{39}$ In this study, we extracted peptides from Jiupei. The ACE inhibitory activity of a peptide is closely related to its composition, hydrophobicity and location of amino acids in the peptide chains. ${ }^{17}$ The activity of an ACE inhibitor is influenced by the amino acid at the Cterminus. Higher inhibition is observed with aromatic amino acids (e.g., tryptophan, tyrosine, and phenylalanine) and proline at the C-terminus. In addition, the inhibitory activity is also higher with a hydrophobic (e.g., valine, leucine, and isoleucine) or basic amino acids at the N-terminus. Except for proline, all of these amino acids have strong affinity with ACE. Highly hydrophilic amino acids have weak or no inhibitory activity because they cannot be located close to the active site of ACE. ${ }^{\mathbf{4 0}}$ In this study, the peptides Tyr-Gly-Asp and Val-Asn-Pro showed strong ACE inhibition, which could be attributed to proline at 
the C-terminus and hydrophobic valine at the N-terminus for Val-Asn-Pro and tyrosine at the N-terminus for Tyr-Gly-Asp. The Tyr-Gly-Asp and Val-Asn-Pro peptides displayed activity against ACE. Both Tyr-Gly-Asp and Val-Asn-Pro have higher ACE inhibitory than Pro-His-Pro ( $\mathrm{IC}_{50}$ value $446 \mu \mathrm{M}$ ), which was extracted from Baijiu, ${ }^{20}$ because both C-terminus and $\mathrm{N}$ terminus of Pro-His-Pro are proline, rather than tyrosine and valine that have high affinity for the ACE active sub-side.

\section{Conclusions}

A method was established for the extraction and separation of peptides from Jiupei used for preparation of sesame flavor-type Baijiu. Two peptides in Jiupei were identified for the first time, while their amino acid sequences (Val-Asn-Pro and Tyr-Gly-Asp) were determined by HPLC-ESI-Q-TOF-MS. Both peptides exhibited high ACE inhibitory activity. These methods and results provide a reference for studying the function of healthy peptides in Jiupei, and the origin of peptides in Baijiu can be studied.

Further studies are required to determine the contents of Val-Asn-Pro and Tyr-Gly-Asp in different types of Jiupei and to evaluate their free radical scavenging activities, protective effects on DNA damage, etc. Cell activities and animal activities are needed to explore their mechanisms of action. Extraction and isolation of other peptides from Jiupei during different stages of Baijiu production by the established method will be useful for comparison purposes. The results could be used to trace the changes in peptides content throughout the Baijiu brewing process. Based on these findings, we can expect to increase in the content of functional peptides in final Baijiu products by optimizing distillation parameters or extracting functional peptides from the material after distillation. These are possible ways to enhance the beneficial effects of Baijiu on human health. Adding these types of peptides to the health-care products shows their additional value.

\section{Ethical approval}

This article does not contain any studies with human or animal subjects.

\section{Informed consent}

Informed consent was obtained from all individual participants included in the study.

\section{Conflicts of interest}

There is no conflict interest.

\section{Abbreviation}

HPLC-Q-TOF-MS/ High performance liquid chromatography MS with quadrupole-time-of-flight-mass spectrometry/mass spectrometry

$\begin{array}{ll}\text { ACE } & \text { Angiotensin-I converting enzyme } \\ \text { SSF } & \text { Solid-state fermentation } \\ \text { RAS } & \text { Renin-angiotensin system } \\ \text { KKS } & \text { Kallikrein-kinin system } \\ \text { UPLC-ESI-Q-TOF- } & \text { Ultra-performance liquid chromatography } \\ \text { MS/MS } & \text { electron spray ionization quadrupole-time- } \\ & \text { of-flight-mass spectrometry/mass } \\ & \text { spectrometry } \\ \text { GSSG } & \text { Oxidized glutathione } \\ \text { SOD } & \text { Superoxide dismutase } \\ \text { CAT } & \text { Catalase } \\ \text { RP-HPLC } & \text { Reversed phase high performance liquid } \\ & \text { chromatography } \\ \text { UV detector } & \text { Ultraviolet detector } \\ \text { Val } & \text { Valine } \\ \text { Asn } & \text { Asparagine } \\ \text { Pro } & \text { Proline } \\ \text { Tyr } & \text { Tyrosine } \\ \text { Gly } & \text { Glycine }\end{array}$

\section{Acknowledgements}

This study was supported by the National Key R\&D Program of China [2017YFC1600401] and the National Natural Science Foundation of China [31301466, 31601556 and 31701567].

\section{References}

1 H. Liu and B. Sun, J. Agric. Food Chem., 2018, 66, 5425-5432.

2 X. Sun, J. Dong, J. Li, M. Ye, W. Zhang and J. Ou, J. Chromatogr. A, 2017, 1498, 72-79.

3 P. Lin, Z. Qin, Z. Yao, L. Wang, W. Zhang, Y. Yu, Y. Dai, H. Zhou and X. Yao, J. Chromatogr. B: Anal. Technol. Biomed. Life Sci., 2018, 1085, 72-88.

4 D. Zhao, J. Sun, B. Sun, M. Zhao, F. Zheng, M. Huang, X. Sun and H. Li, RSC Adv., 2017, 7, 46395-46405.

5 B. Sun, H. Li, X. Hu, J. Sun and D. Wei, J. Chin. Inst. Food Sci. Technol., 2016, 16, 1-6.

6 W. Zhang, G. Si, M. Ye, S. Feng, F. Cheng, J. Li, J. Mei, S. Zong, J. Wang and P. Zhou, Food Anal. Methods, 2017, 1-9.

7 A. B. Nongonierma and R. J. Fitzgerald, RSC Adv., 2016, 6, 75400-75413.

8 S. Rudolph, D. Lunow, S. Kaiser and T. Henle, Food Chem., 2017, 224, 19-25.

9 M. Hajfathalian, S. Ghelichi, P. J. Garcíamoreno, A. S. Moltke and C. Jacobsen, Crit. Rev. Food Sci. Nutr., 2017, 1, 1-33.

10 J. Wu, B. Sun, X. Luo, M. Zhao, F. Zheng, J. Sun, H. Li, X. Sun and M. Huang, RSC Adv., 2018, 8, 10898-10906.

11 I. Irshad, A. Kanekanian, A. Peters and T. Masud, J. Food Sci. Technol., 2015, 52, 231-239.

12 M. Z. Haque Bhuyan, Y. Tamura, E. Sone, Y. Yoshinari, C. Maeda, M. Takahashi, Y. Tabata, R. Murali, Y. Waki and K. Aoki, J. Pharmacol. Sci., 2017, 134, 124-130.

13 H. Miyazaki, T. Nakamura, K. Ohki and K. Nagai, Auton. Neurosci., 2017, 208, 88-92. 
14 A. Chatterjee, S. K. Kanawjia, Y. Khetra and P. Saini, J. Food Sci. Technol., 2015, 52, 5621-5630.

15 M. Shakerian, S. H. Razavi, S. A. Ziai, F. Khodaiyan, M. S. Yarmand and A. Moayedi, J. Food Sci. Technol., 2015, 52, 2428-2433.

16 D. Solanki and S. Hati, Food Biosci., 2018, 23, 16-22.

17 M. Tu, C. Wang, C. Chen, R. Zhang, H. Liu, W. Lu, L. Jiang and M. Du, Food Chem., 2018, 256, 98-104.

18 A. Moayedi, L. Mora, M. C. Aristoy, M. Safari, M. Hashemi and F. Toldrá, Food Chem., 2018, 250, 180-187.

19 J. Wu, B. Sun, M. Zhao, F. Zheng, J. Sun, X. Sun, H. Li and M. Huang, J. Chin. Inst. Food Sci. Technol., 2016, 16, 14-20.

20 J. Wu, J. Huo, M. Huang, M. Zhao, X. Luo and B. Sun, J. Agric. Food Chem., 2017, 65, 10495-10504.

21 Z. Liu and J. Pan, Food Chem., 2017, 224, 289-293.

22 L. Wang, Y. Ding, X. Zhang, Y. Li, R. Wang, X. Luo, Y. Li, J. Li and Z. Chen, Food Chem., 2018, 239, 416.

23 T. Masuko, A. Minami, N. Iwasaki, T. Majima, S. I. Nishimura and C. L. Yuan, Anal. Biochem., 2005, 339, 69-72.

24 F. Han, Y. U. Ting-Ting and M. L. Zhou, J. Agric. Sci. Technol., 2008, 10, 110-117.

25 S. Toelstede, A. Dunkel and T. Hofmann, J. Agric. Food Chem., 2009, 57, 1440.

26 H. R. Vulupala, Y. Sajja, P. K. Bagul, R. Bandla, L. Nagarapu and S. K. Benerjee, Bioorg. Chem., 2018, 77, 660.
27 A. B. Nongonierma and R. J. FitzGerald, Innovative Food Sci. Emerging Technol., 2017, 43, 239-252.

28 F. Hou, W. Ding, W. Qu, A. O. Oladejo, F. Xiong, W. Zhang, R. He and H. Ma, Food Chem., 2017, 218, 207-215.

29 C. Álvarez, P. Lélu, S. Lynch and B. K. Tiwari, LWT-Food Sci. Technol., 2018, 88, 210-216.

30 A. Abedinia, A. M. Nafchi, F. Ariffin and N. Huda, Int. J. Biol. Macromol., 2017, 98, 586-594.

31 S. U. Kadam, B. K. Tiwari, C. Álvarez and C. P. O'Donnell, Trends Food Sci. Technol., 2015, 46, 60-67.

32 S. Suwal, S. Ketnawa, A. M. Liceaga and J.-Y. Huang, Innovative Food Sci. Emerging Technol., 2018, 45, 122-131.

33 R. He, A. T. Girgih, E. Rozoy, L. Bazinet, X. R. Ju and R. E. Aluko, Food Chem., 2016, 197, 1008-1014.

34 M. Zhuang, L. Lin, M. Zhao, Y. Dong, D. Sun-Waterhouse, H. Chen, C. Qiu and G. Su, Food Chem., 2016, 206, 174-181.

35 J. Liu, H. Song, Y. Liu, P. Li, J. Yao and J. Xiong, J. Sci. Food Agric., 2015, 95, 3183-3194.

36 F. L. Han and Y. Xu, J. Inst. Brew., 2012, 117, 238-250.

37 V. Luca, H. L. Bianchi, F. Allevatto, J. O. Vaccaro and A. Alvarado, J. Environ. Chem. Eng., 2017, 5, 4165-4172.

38 Y. Zheng, Y. Li, Y. Zhang, X. Ruan and R. Zhang, J. Funct. Foods, 2017, 28, 48-58.

39 L. You, M. Zhao, J. M. Regenstein and J. Ren, Food Res. Int., 2010, 43, 1167-1173.

40 M. Kohmura, N. Nio and Y. Ariyoshi, Agric. Biol. Chem., 2014, 54, 1101-1102. 